\title{
SCIDOC
}

International Journal of Dentistry and Oral Science (IJDOS)

ISSN: 2377-8075

\section{Importance Of Glycemic Controlin Individuals With Type 2 Diabetes and Oral Cancer}

Rajendra Prabhu Abhinav ${ }^{1,2^{*}}$, Rajendra Pradeepa ${ }^{1}$, Ranjit Mohan Anjana ${ }^{1}$, Viswanathan Mohan ${ }^{1}$

${ }^{1}$ Madras Diabetes Research Foundation, Chennai, India.

${ }^{2}$ Saveetha Dental College and Hospital, Chennai, India.

\section{Abstract}

Globally, the prevalence/incidence of type 2 diabetes and oral cancer has increased dramatically in the past few decades. Studies have shown that type 2 diabeteshas an elevated risk of oral cancer, mediated by promoting DNA damage through oxidative stress caused by an increased mitochondrial glucose oxidation.Few studies have shown that higherglycated hemoglobin (HbA1c) levels increase the risk of certain cancers including cancers of oral cavity. Glycemic control, believed to be one of the causes of the outcome differences between cancer patients with and without diabetes, plays an important role in health related quality of life, recurrence of cancer, severity of symptomand pain,risk for infections, increased hospitalization and stay and lead to stoppage or reduction in dose of chemotherapy, which can lead to poor outcomes and reduce the lifespan. Very few studies have evaluated the link between oral cancer and $\mathrm{HbA1c}$ and the findings are equivocal. Thus, to increase the survival and improve the health outcomesinindividuals with oral cancer and diabetes, the role of glycemic control must be further elucidated and studies are urgently needed on this topic.

Diabetes and cancer are non-communicable diseases with huge impact on health worldwide [1]. According to the recent GLOBOCAN report, globally, an estimated 19.3 million new cancer cases and almost 10.0 million cancer deaths have occurred in 2020 [2]. While the International Diabetes Federation (IDF) has reported that in 2019, 463 million had diabetes and mortality attributable to diabetes and associated complications in adults was 4.2 million [3]. In 2020, oral cancer which include cancers of the mucosal lip, tongue, gum, floor of the mouth, palate and mouth was reported as the sixteenth most common form of cancer in the world with 377,713 new cases and 177,757 deaths [2]. There are evidences to substantiate the link between diabetes and the increased prevalence and progression of various cancers including cancers of the breast,colon, lung, prostate, pancreasand oral cavity $[4,5]$. The prevalence of co-existing diabetes among newly diagnosedcancer patients varies from 8 to $18 \%$ [6].

The common diabetes associated complications include microvascular complications (retinopathy, nephropathy and neuropathy) and macrovascular complications (cardiovascular disease, peripheral vascular disease and cerebrovascular disease) [7]. However, recently'diabetic oncopathy' has been implicated as one of the complications of diabetes [8].The biological mechanisms underlying the association between cancer and diabetes have been debated and are not clear. It has been suggested that hyperglycemia could be one of the underlying mechanisms for the association between diabetes and cancer risk by promoting DNA damage through oxidative stress caused by an increased mitochondrial glucose oxidation $[9,10]$. It is also a known promoter of oncogenesis and metastasis [10]. Other possible mechanisms for a direct link between these two conditions include hyperinsulinemia and inflammation $[4,5]$.

Some studies link higherglycated hemoglobin (HbA1c) levels, one of the key biomarkers in identifying patients with diabetes and a reflective measure of blood glucose values over a period of about 3 months, and other measures of hyperglycemia to increased risk of certain cancers [11-13]. Glycemic control is also hypothesized as one of the causes of the outcome differences between cancer patients with and without diabetes. Glycemic control was found

\section{*Corresponding Author:}

Rajendra Prabhu Abhinav, (Oral \& Maxillo-facial Surgery)

Assistant Professor, Department Of Implantology, Saveetha Dental College And Hospital, No.162, Poonamallee High Road, Chennai-600077 \&Research Fellow, Madras Diabetes Research Foundation, No. 4, Conran Smith Road,Gopalapuram, Chennai - 600 086, India.

Tel: 9940142823

Fax: (9144) 28350935

E-mail: trilokabhinav@Gmail.com

Received: March 28, 2021

Accepted: July 09, 2021

Published: July 28, 2021

Citation: Rajendra Prabhu Abhinav, Rajendra Pradeepa, Ranjit Mohan Anjana, Viswanathan Mohan. Importance Of Glycemic Controlin Individuals With Type 2 Diabetes and Oral Cancer. Int J Dentistry Oral Sci. 2021;8(7):3497-3499. doi: http://dx.doi.org/10.19070/2377-8075-21000714

Copyright: Rajendra Prabhu Abhinav 2021. This is an open-access article distributed under the terms of the Creative Commons Attribution License, which permits unrestricted use, distribution and reproduction in any medium, provided the original author and source are credited. 
to play an important role in the level of health-related quality of life experienced, level of symptom, severity experienced, which can influence the survival of the individual with cancerand diabetes [14]. Several studies have assessed the relationship between glycemic control and various cancers including pancreatic cancer, lung cancer, gastroesophagealcancer etcand the results are equivocal [15-18]. It has also been reported that with increasing HbA1c levels, there is increased risk for higher cancer stage and cancer pre-cursor incidence for some cancer types [18]. However, data on glycemic control and oral cancer are very sparse.

Oral cancer is one of the main causes for morbidity worldwide. Oral squamous cell carcinoma (OSCC) is the most prevalent oral malignancy, representing up to $80-90 \%$ of all malignant neoplasms of the oral cavity [19]. The most common sites of oral cancer in the European and the American population are the tongue, whileoral cancer in thebuccal mucosa is commonly seen in the Southeast Asian and Indian region. Moist snuff kept between the buccal mucosa and gingival region, is attributed to the development of cancers of the buccal mucosa [20]. The 5-year survival rate is close to $50 \%$ after cancer treatment. The best prognosis and 5-year survival rate are seen for cancers of the lip region [21]. Hyperglycaemia has been reported to increase the risk of oral cancer by two-fold [22]. Tay et al [23], investigated the relationship between preoperative HbA1c levels and OSCCon treatment outcomesin 89 patients with OSCC who were diagnosed with diabetes. This study reported that OSCC patients with higher HbA1c levels had longer hospitalizationand intensive care unitstays. In addition, these patients also had significantly worse survival outcomes, which included increased rates of locoregional recurrence, distant metastases and development of second primary tumors.

A US based study which examined the impact of diabetes on survival ofpatients with OSCC and the impact of OSCC on glycemic control, reported that the 5 -year overall survival was $61 \%$ in patients with diabetes compared to $78 \%$ in those without diabetes. Regarding HbA1c, it significantly decreasedover time and OSCC did not affect glycemic control [24].Similarly, the New Zealand population-based linkage study [13], which assessed the association between $\mathrm{HbA} 1 \mathrm{c}$ levels and cancer risk in 46575 participants with a median follow-up of 4.4 years reported that oral and digestive cancersmade up $18 \%$ of new cancer cases. However,a non-significant $17 \%$ increasewas observed in persons with higher HbA1c levels ( $\geq 7 \%$ ) [HR 1.17, 95\% CI: 0.60-2.28) as compared with personshaving normal HbA1c levels.

From the available literature it is observed that not many studies have looked at the role of $\mathrm{HbA1c}$, as a risk factor for development of oral cancers and its outcomes in patients with diabetes. In general, improving the glycemic control in individuals with diabetes and any type of cancer,including oral cancer, may improve the prognosis, reduce complications in those undergoing cancer therapy and decreasemortality. Glycemic control can affect an individual's ability to complete treatment as well as their survival and end-of-life quality [25]. Management of the duo, i.e., diabetes and cancer, is a great challenge for health care providers. Hershey et al [26] has reported that individuals with diabetes and cancer give priority to cancer management over their diabetes care. This could affect their glycemic status and increase their risk for mortality [27]. Individuals with both the disorders have a higher prevalence of non-adherence to oral anti-diabetic agents compared to those only with diabetes, which may lead touncontrolled diabetes/poor glycemic control. Adherence to oral agents is associated with $24 \%$ fewer hospitalizations in cancer patients with diabetes [28].

Studies have also shown that chemotherapy and corticosteroids used for cancer therapy can affect glycemic control leading to poor outcomes $[26,29]$. Similarly, it has been reported that individuals with type 2 diabetes and cancer with poor glycemic control were more likely to develop infections orrequire hospitalization, or a chemotherapy dose reduction or stoppage [30]. In addition, it also increases symptom and pain severity. Based on the available literature, Figure 1 presents the potential effects of poor glycemic control in individuals with diabetes and oral cancer.

To increase the lifespan and improve the quality of lifeinindividuals with oral cancer and diabetes, the role of glycemic control must be further elucidated.Awareness and management of the glycemic status of individuals with cancer and diabetes should be part of the patients' treatment plan right from the day of diagnosis.Education should be targeted to enhance health outcomes in thosewith diabetes and cancer which addresses the "cause" not just the "source" of the problem. HbA1c appears to be associated with oral cancer incidence and/or mortality, however, further studies areneeded to fully understand the relationship between oral cancerand $\mathrm{HbA} 1 \mathrm{c}$ and this is an urgent unmet need in research.

Figure 1. Potential effects of poor glycemic control in individuals with diabetes and oral cancer.

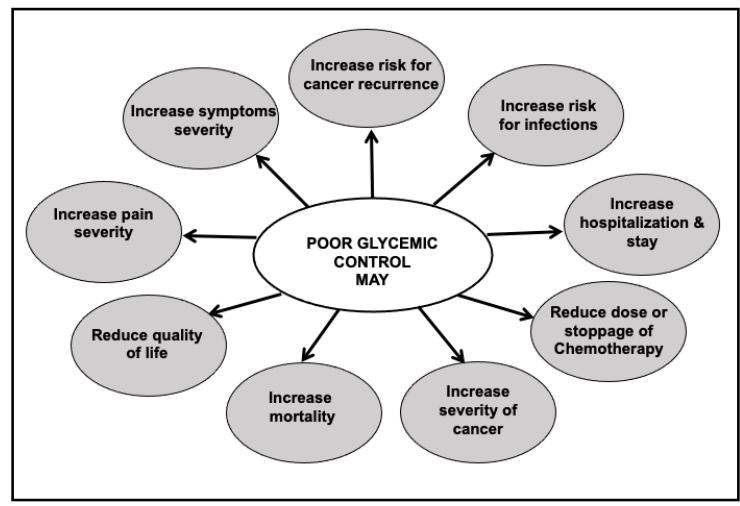




\section{References}

[1]. World Health Organization; Non communicable disease.Accessed on 6th March 2021

[2]. Sung H, Ferlay J, Siegel RL, Laversanne M, Soerjomataram I, Jemal A, et al. Global cancer statistics 2020: GLOBOCAN estimates of incidence and mortality worldwide for 36 cancers in 185 countries. CA Cancer J Clin. 2021 Feb 4. Pubmed PMID: 33538338.

[3]. Federation ID. IDF Diabetes Atlas, 9th edn. Brussels, Belgium. 2019.

[4]. Giovannucci E, Harlan DM, Archer MC, Bergenstal RM, Gapstur SM, Habel LA, et al. Diabetes and cancer: a consensus report. Diabetes Care. 2010 Jul;33(7):1674-85. Pubmed PMID: 20587728.

[5]. Abhinav RP, Williams J, Livingston P, Anjana RM, Mohan V. Burden of diabetes and oral cancer in India. J Diabetes Complications. 2020 Nov;34(11):107670. Pubmed PMID: 32651032.

[6]. Ko C, Chaudhry S. The need for a multidisciplinary approach to cancer care. J Surg Res. 2002 Jun 1;105(1):53-7. Pubmed PMID: 12069502.

[7]. Pradeepa R, Mohan V. Prevalence of type 2 diabetes and its complications in India and economic costs to the nation. Eur J Clin Nutr. 2017 Jul;71(7):816824. Pubmed PMID: 28422124.

[8]. Balasubramanyam M. Diabetic oncopathy--one more yet another deadly diabetic complication! Indian J Med Res. 2014 Jul;140(1):15-8. Pubmed PMID: 25222773

[9]. Kasuga M, Ueki K, Tajima N, Noda M, Ohashi K, Noto H, et al. Report of the Japan Diabetes Society/Japanese Cancer Association Joint Committee on Diabetes and Cancer. Cancer Sci. 2013 Jul;104(7):965-76. Pubmed PMID: 23879470

[10]. Duan W, Shen X, Lei J, Xu Q, Yu Y, Li R, et al. Hyperglycemia, a neglected factor during cancer progression. Biomed Res Int. 2014;2014:461917. Pubmed PMID: 24864247.

[11]. Johnson JA, Bowker SL. Intensive glycaemic control and cancer risk in type 2 diabetes: a meta-analysis of major trials. Diabetologia. 2011 Jan;54(1):2531. Pubmed PMID: 20959956.

[12]. Joshu CE, Prizment AE, Dluzniewski PJ, Menke A, Folsom AR, Coresh J, et al. Glycated hemoglobin and cancer incidence and mortality in the Atherosclerosis in Communities (ARIC) Study, 1990-2006. Int J Cancer. 2012 Oct 1;131(7):1667-77. Pubmed PMID: 22161730

[13]. Travier N, Jeffreys M, Brewer N, Wright CS, Cunningham CW, Hornell J, et al. Association between glycosylated hemoglobin and cancer risk: a New Zealand linkage study. Ann Oncol. 2007 Aug;18(8):1414-9. Pubmed PMID: 17693655.

[14]. Hershey DS. Importance of Glycemic Control in Cancer Patients with Diabetes: Treatment through End of Life. Asia Pac J Oncol Nurs. 2017 OctDec;4(4):313-318. Pubmed PMID: 28966959.

[15]. Rentsch CT, Farmer RE, Eastwood SV, Mathur R, Garfield V, Farmaki AE, et al. Risk of 16 cancers across the full glycemic spectrum: a populationbased cohort study using the UK Biobank. BMJ Open Diabetes Res Care. 2020 Aug;8(1):e001600. Pubmed PMID: 32859587.
[16]. Boursi B, Giantonio BJ, Lewis JD, Haynes K, Mamtani R, Yang YX. Serum glucose and hemoglobin A1C levels at cancer diagnosis and disease outcome. Eur J Cancer. 2016 May;59:90-98. Pubmed PMID: 27017290.

[17]. Miao Jonasson J, Cederholm J, Eliasson B, Zethelius B, Eeg-Olofsson K, Gudbjörnsdottir S. HbA1C and cancer risk in patients with type 2 diabetes-a nationwide population-based prospective cohort study in Sweden. PLoS One. 2012;7(6):e38784. Pubmed PMID: 22719946.

[18]. de Beer JC, Liebenberg L. Does cancer risk increase with HbA1c, independent of diabetes? Br J Cancer. 2014 Apr 29;110(9):2361-8. Pubmed PMID: 24675382.

[19]. Lingen MW, Kalmar JR, Karrison T, Speight PM. Critical evaluation of diagnostic aids for the detection of oral cancer. Oral Oncol. 2008 Jan;44(1):1022. Pubmed PMID: 17825602.

[20]. Gupta N, Gupta R, Acharya AK, Patthi B, Goud V, Reddy S, et al. Changing Trends in oral cancer - a global scenario. Nepal J Epidemiol. 2016 Dec 31;6(4):613-619. Pubmed PMID: 28804673.

[21]. Pruegsanusak K, Peeravut S, Leelamanit V, Sinkijcharoenchai W, Jongsatitpaiboon J, Phungrassami T, et al. Survival and prognostic factors of different sites of head and neck cancer: an analysis from Thailand. Asian Pac J Cancer Prev. 2012;13(3):885-90. Pubmed PMID: 22631666.

[22]. Sen MP, Shenoy N, Shenoy AK, Adhikari P, Ahmed J, Yadiyal AM. Diabetes Mellitus and Oral Cancer: Are They Connected?. Indian Journal of Oral Health and Research. 2015 Jan 1;1(1):4.

[23]. Tay ZY, Kao HK, Lien KH, Hung SY, Huang Y, Tsang NM, et al. The impact of preoperative glycated hemoglobin levels on outcomes in oral squamous cell carcinoma. Oral Dis. 2020 Oct;26(7):1449-1458. Pubmed PMID: 32426892.

[24]. Ederaine SA, Dominguez JL, Harvey JA, Mangold AR, Cook CB, Kosiorek $\mathrm{H}$, et al. Survival and glycemic control in patients with co-existing squamous cell carcinoma and diabetes mellitus. Future Science OA. 2021 $\operatorname{Jan}(0)$ :FSO683.

[25]. Hershey DS. Importance of Glycemic Control in Cancer Patients with Diabetes: Treatment through End of Life. Asia Pac J Oncol Nurs. 2017 OctDec;4(4):313-318. Pubmed PMID: 28966959.

[26]. Hershey DS, Tipton J, Given B, Davis E. Perceived impact of cancer treatment on diabetes self-management. Diabetes Educ. 2012 NovDec;38(6):779-90. Pubmed PMID: 22983823.

[27]. Liu X, Ji J, Sundquist K, Sundquist J, Hemminki K. The impact of type 2 diabetes mellitus on cancer-specific survival: a follow-up study in Sweden. Cancer. 2012 Mar 1;118(5):1353-61. Pubmed PMID: 21800292.

[28]. Tan X, Feng X, Chang J, Higa G, Wang L, Leslie D. Oral antidiabetic drug use and associated health outcomes in cancer patients. J Clin Pharm Ther. 2016 Oct;41(5):524-31. Pubmed PMID: 27453485.

[29]. Psarakis HM. Clinical challenges in caring for patients with diabetes and cancer. Diabetes Spectrum. 2006 Jul 1;19(3):157-62.

[30]. Hope C, Robertshaw A, Cheung KL, Idris I, English E. Relationship between HbAlc and cancer in people with or without diabetes: a systematic review. Diabet Med. 2016 Aug;33(8):1013-25. Pubmed PMID: 26577885. 